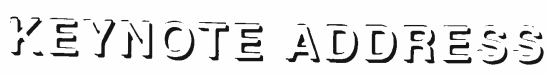

\section{SIMULATION, TECHNOLOGY, AND THE DECISION PROCESS}

\author{
Philip J. Kiviat \\ Chartway Technologies \\ 20 West Gude Drive \\ Rockville, Maryland 20850-1150
}

\begin{abstract}
In 1967, the first Winter Simulation Conference (WSC) was heavily concerned with simulation languages, modeling, and model validation issues. People were just starting to come to grips with basic modeling and simulation concepts, and appreciate the advantage of simulation languages for providing a "world view," conveying concepts and improving model building productivity. Simulation was presented as a major tool for management, but tools were not in place to readily deliver on the promise.

Now, 23 years later, simulation tools abound. Many related statistical problems have been solved, or approaches to them developed. Last year's WSC was particularly heavy in applications papers, showing a continuing strong interest in putting simulation methods to use in extraordinarily diverse application areas. Are we now where we wanted, or expected, to be 20 years ago? Is simulation technology up to the level it should be to address today's problems? Is simulation accepted in practice as a dependable, cost-effective management decision aid? Is simulation even understood by the decision-makers we have pledged our careers to support, or is it, by its similarity to the widespread use of decision support systems, spreadsheets and computer animation, in danger of
\end{abstract}

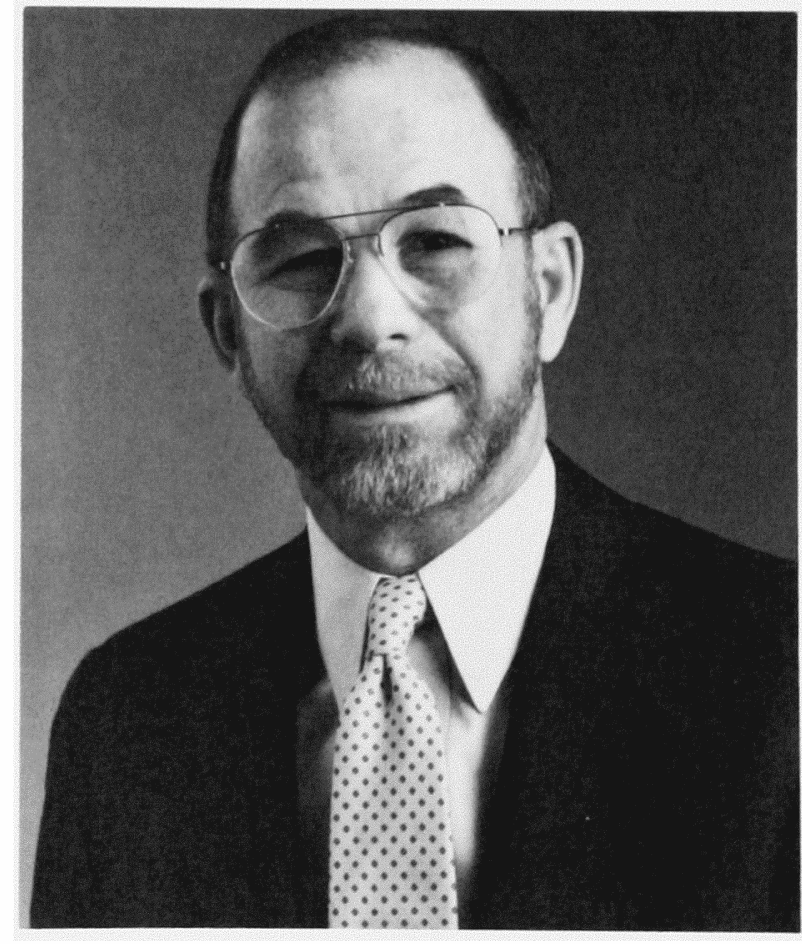

being dangerously misunderstood and misused?

This talk will look at the practice of discrete-event simulation over the past 25 years, with a passing glance at continuous systems simulation, and make some observations about where we are, where we should be, and what we should be striving to achieve. 